\title{
The concept of a novel transcatheter aortic valve
}

\author{
Piotr Chodór ${ }^{1}$, Krzysztof Wilczek $^{2}$, Zbigniew Kalarus ${ }^{1}$ \\ ${ }^{1}$ Department of Cardiology, Congenital Heart Diseases and Electrotherapy, Medical University of Silesia, Silesian Center for Heart Diseases, \\ Zabrze, Poland \\ ${ }^{2} 3^{\text {rd }}$ Department of Cardiology, Medical University of Silesia, Silesian Center for Heart Diseases, Zabrze, Poland
}

Adv Interv Cardiol 2020; 16, 4 (62): 482-485

DOI: https://doi.org/10.5114/aic.2020.101776

\section{Introduction}

Recently published studies comparing transcatheter aortic valve implantation (TAVI) with surgical aortic valve replacement (SAVR) are very encouraging. The PARTNER 3 study revealed that TAVI showed an advantage over the surgical procedure in terms of composite endpoints in a 30-day and 1-year follow-up. The Evolut Low Risk Trial showed that TAVI is not inferior to SAVR in a 2-year follow-up. Currently, Sapien 3 and Evolut $R$ are approved by the FDA for use in low-risk patients [1, 2]. As a result, the indications for TAVI will most likely be extended in future recommendations. It will also mean that TAVI will be used in ever-younger patients.

As younger patients are qualified for the procedure, the importance of access to coronary arteries will increase. Access to coronary arteries depends both on anatomical factors and the applied procedure [3]. The compatibility of the new commissures with the native commissures constitutes another issue. Surgical valves are compatible with the new commissures in $96 \%$ of cases, and the valves implanted using TAVI are fully or partially compatible only in $47 \%$ of cases [4]. Proper orientation of the new commissures in relation to the native ones reduces valve coverage of the coronary ostia, facilitating access to the coronaries in future interventions [4]. It can also impact valve durability by reducing central regurgitation and transvalvular shear stress [5].

\section{Assumptions of the concept of the novel aortic valve}

1. The valve is made of Nitinol

2. It is self-expanding, repositionable, retrievable, rotatable
3. The shape of the valve frame with three arms ensures free access to coronary arteries (Figure $1 \mathrm{~A}$ )

4. The shape of the base is cylindrical in order to ensure predictable oversizing at the annulus level (Figure 1 A) [6]

5. Additional markers with different shapes at the base ensure correct positioning of the valve during implantation, in alignment with the native commissures (Figure $1 \mathrm{~A}, 2 \mathrm{~A}$ )

6. Correct implantation of the new valve requires determination of the position of the $X$-ray tube, in which the lower markers are visible in the correct order, in a single line and at equal distances from each other

7. The height of the stent is relatively low $(12 \mathrm{~mm}$ from the base to the lowest point of the area between the arms of the stent) (Figures 2 C-E)

8. The valve can be used in patients with a bicuspid aortic valve

9. The valve is resistant to deformation during resuscitation

\section{Implantation process}

Before the implantation, it is necessary to determine the position of the X-ray tube amplifier, in which the bottoms of three aortic sinuses are visible at equal distances and in a single line (Figure $1 \mathrm{~B}$ - red arrows). It is the same position where three places of attachment of commissures to the aortic bulb wall are visible (Figure $1 \mathrm{~B}$ - blue arrows).

The course of the implantation procedure would be similar to the implantation of the currently known self-expanding valves. The assembled valve would be expanded by sliding the sheath until the lower markers are visible (Figure $1 \mathrm{E}$ ). As the shapes of the lower markers vary, it is possible to differentiate between them under X-rays (Figure $2 \mathrm{~A}$ ). The identification of markers makes it possible

\section{Corresponding author:}

Piotr Chodór MD, Department of Cardiology, Congenital Heart Diseases and Electrotherapy, Medical University of Silesia, Silesian Center for Heart Diseases, Zabrze, Poland, phone: +48 3227353 56, e-mail: chodor_piotr@go2.pl

Received: 14.05.2020, accepted: 5.09.2020. 
to determine whether the middle marker is in the front or in the back (Figure $1 \mathrm{C}$ ). When markers are identical, it is impossible to reliably determine whether the middle marker is in the front or in the back (Figure $1 \mathrm{D}$ ). Sliding the sheath further makes the markers more visible and makes it possible to confirm their identification as well as making sure that they are in a single line and at an equal distance from each other. If the markers are not in the correct order or the distance between them is not equal, the valve can be reassembled, turned and adjusted to match the commissures of the native valve (Figure $1 \mathrm{~F}$ ). The valve can simply be turned, by no more than $60^{\circ}$ in one direction, for the commissure of the new valve to match the native commissure. After the adjustment of the position of the valve, the implantation is initiated again by removing the cover. Full expansion of the valve will enable its positioning in alignment with the commissures, and the spaces between the valve arms will ensure free access to coronary arteries in the future (Figure 2 B).

Figures 2 C-E present various valve solutions, depending on the numbers of mesh rows in the valve frame.

\section{Discussion}

Our concept and solution ensures that the commissures of the new valve and the commissures of the na- tive valve are aligned, regardless of the number of calcifications, or the presence of a bicuspid or one-cuspid valve. Valve orientation will be as precise as the surgically implanted valves. Due to the open space between the arms and the low height of the stent, the structure will facilitate access to coronary arteries in the future. Repositioning will ensure precise implantation and the possibility of correction of the valve's position, if required. Adjustment of the commissures will reduce paravalvular leaks and transvalvular shear stress, which may be important for valve durability. All these features are increasingly important for the ever-younger patients undergoing TAVI.

The aim of adjusting the commissures of the implanted valve to match the native commissures can be achieved in various ways. Blumenstein described attempts to match the commissures of the Sapien XT using a transapical approach. Due to the tendency to limit the apical approach, this method of implantation of a valve aligned with the native commissures is not being developed. Furthermore, in the case of Edwards Sapien $\mathrm{XT}$ implantation, even when it is aligned with the commissures, access to coronary arteries may be limited by structural elements of the valve stent if the valve is implanted in a high position [7].
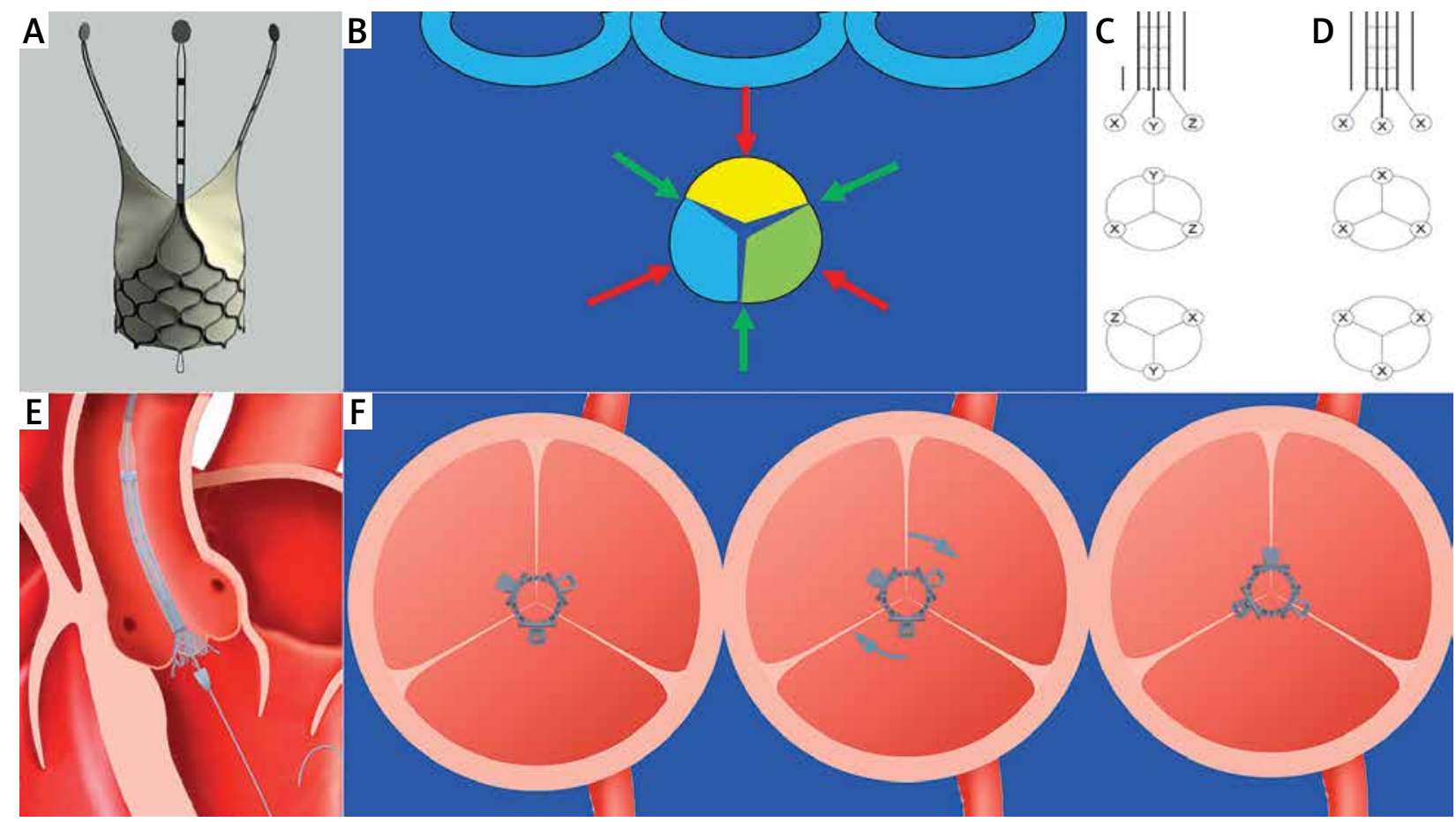

Figure 1. Valve concept and implantation process: A - valve design, B - projections (green and red arrows) where the bottoms of three sinuses and commissures are visible in a single line and at equal distances from each other; green dots - commissures, C - varied shapes of lower markers make it possible to identify their position and check whether the middle marker is in the front or in the back, $\mathbf{D}$ - identical markers make it impossible to identify the position of lower markers; the middle marker can be both in the front and in the back, $\mathbf{E}$ - initial stage of valve implantation, $\mathbf{F}$ - the valve can be turned, which enables its adjustment to match the native commissures 


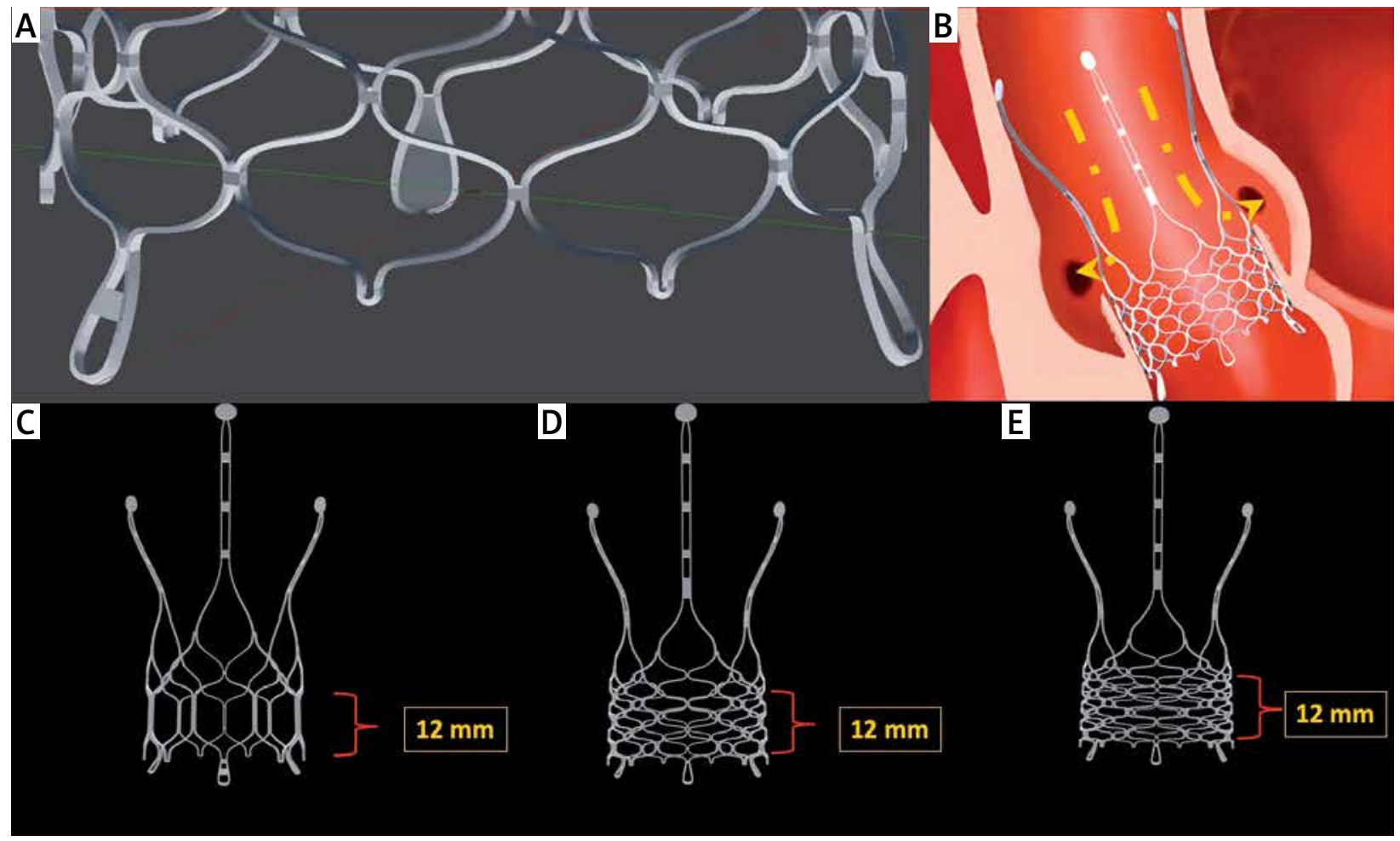

Figure 2. Valve concept and implantation process: A - varied lower markers can be identified under X-rays, B - the implanted valve enables free access to coronary arteries, C-E - different variants of the valve, depending on the number of mesh rows

The design of new valves, such as J-Valve and the new version of Jena-Valve, assumes matching the commissures of the implanted valve with the commissures of the native valve. Both grasp the cusps of the native valve during the implantation and thus become aligned with the commissures. Therefore, when properly implanted, they should provide free access to coronary arteries due to the lack of elements opposite the ostia of coronary arteries. The experience concerning these valves is limited. They are non-repositionable and it is impossible to predict the course of the process of implantation in patients with a bicuspid aortic valve, which is more common in younger age groups, or in patients with massive calcifications of aortic valve cusps. There are attempts to position the valves in accordance with the native commissures using fluoroscopically visible markers present on the valves: the "Hat" marker in Evolut R, the existing commissural pots attached to the stent in Sapien 3 and ACURATE neo [8]. In the case of Sapien 3, various attempts at initial crimping orientation of the valves on the delivery system did not improve the adjustment of the new commissures to those of the native valve. In $51.3 \%$ of the cases, there was a severe coronary artery overlap in one or two coronary orifices. It was observed that at specific positions of the "Hat" marker of Evolut $R$ and commissural pots in the case of the ACCURATE valve, severe coronary artery overlap is less frequent, but it is still present in $23.4 \%$ of cases when using Evolut $\mathrm{R}$ and in $12.5-14.3 \%$ of cases when ACCURATE-neo is used [8]. Attempts were made to intentionally achieve these positions by appropriate adjustment of the delivery system in the case of Evolut $R$, and active rotation in the site of implantation, which was achieved in 5 out of 7 cases when ACCURATE-neo was implanted.

Due to various markers and the ability of the valve to rotate, our solution enables precise valve implantation in alignment with the native commissures. Furthermore, Sapien 3 and ACCURATE-neo are non-repositionable. As far as these valves are concerned, there is also the issue of high implantations, low height of the aortic bulb and low coronary artery ostia. Our solution makes it possible to reposition the valve in case of its abnormal implantation. The low height of the stent $(12 \mathrm{~mm})$ as well as the area between the arms of the stent provide access to coronary arteries in the future.

The project is protected by patent application No. PTC/PL/2017/000105. Details of the solution are provided in the patent application ( $N$ WO2018/080328) [9].

\section{Conclusions}

The novel valve retains the advantages of the existing valves: self-expandability, repositionability and retrievability. At the same time, it solves the problems whose significance increases when the indications are extended to younger patients: it provides access to coronary arteries, and precise, personalized implantation makes 
it possible to adjust its spatial alignment to match the native commissures. Commissural adjustment will affect the durability of the valves.

\section{Conflict of interest}

Chodór $\mathrm{P}$ is consultant of Baltona and was supported by Stamina in the legal protection of the project. Others authors declare no conflict of interest.

\section{References}

1. Mack MJ, Leon MB, Thourani VH, et al. Transcatheter aortic-valve replacement with a balloon-expandable valve in low-risk patients. N Engl J Med 2019; 380: 1695-705.

2. Popma JJ, Deeb GM, Yakubov SJ, et al. Transcatheter aortic-valve replacement with a self-expanding valve in low-risk patients. N Engl J Med 2019; 380: 1706-15.

3. Yudi MB, Sharma SK, Tang GHL, et al. Coronary angiography and percutaneous coronary intervention after transcatheter aortic valve replacement. J Am Coll Cardiol 2018; 71: 1360-78.

4. Fuchs A, Kofoed KF, Yoon SH, et al. Commissural alignment of bioprosthetic aortic valve and native aortic valve following surgical and transcatheter aortic valve replacement and its impact on valvular function and coronary filling. JACC Cardiovasc Interv 2018; 11: 1733-43.

5. Bailey J, Curzen N, Bressloff NW. The impact of imperfect frame deployment and rotational orientation on stress within the prosthetic leaflets during transcatheter aortic valve implantation. J Biomech 2017; 53: 22-8.

6. Chodór P, Wilczek K, Przybylski R, et al. Impact of CoreValve size selection base on multi-slice computed tomography on paravalvular leak after transcatheter aortic valve implantation. Cardiol J 2017; 24: 467-76.

7. Blumenstein JM, Van Linden A, Moellmann H, et al. DynaCTguided anatomical rotation of the SAPIEN XT valve during transapical aortic valve implantation: proof of concept. Thorac Cardiovasc Surg 2013; 61: 409-13.

8. Tang GHL, Zaid S, Fuchs A, et al. Alignment of transcatheter aortic-valve neo-commissures (ALIGN TAVR). JACC Cardiovasc Interv 2020; 13:1030-42.

9. https://patentscope.wipo.int/search/en/detail.jsf?docld=WO 2018080328\&redirectedID=true. Last access date 27/08/2020. 